\title{
A Lesson in Service Learning and Community Engagement
}

\author{
DARSHAN M.A. KARWAT, LAURA S. SHERMAN, LAURA COLE, \\ KRISTA C. BADIANE, PAUL J. COSEO, AND LARISSA S. LARSEN \\ Volume 1, Fall 2013
}

DOI: http://dx.doi.org/10.3998/mjs.12333712.0001.011

\section{ABSTRACT}

Our service-learning course focused on a polluted and impoverished Detroit neighborhood and taught all involved with the class—students, academics, and practitioners - the powerful impact that studio immersions in communities can have on the learning outcomes for students. Through this experience, we learned that in order to make broad notions of sustainability more tangible to students and community residents, they must be enacted through the lens of localized issues.

\section{Introduction}

Learning about sustainability solely in a classroom-based setting can make it difficult for students to understand the ways in which theoretical sustainability principles unfold when they are applied in distressed neighborhoods and urban environments (Dewar and Isaac 1998; Roakes and Norris-Tirrell 2000; Umemoto 2001). Indeed, it is difficult to get a sense of what a polluted situation looks and feels like in a city such as Detroit, when sitting in a classroom at the University of Michigan in Ann Arbor. Specifically, classroom-based learning makes it challenging for instructors to tangibly convey to students the multitude of scales-neighborhood, local, regional, national —at which sustainability must be considered, and how onthe-ground socioeconomic realities and injustices (e.g., poverty, poor health, and unequal access to education) can make addressing sustainability issues an especially complex endeavor. It was precisely these challenges that we chose to address in our undergraduate, interdisciplinary sustainability course. We, five doctoral fellows from different academic units and a faculty member from urban planning, orga- 
nized and taught this service-learning course for twenty-five undergraduates from a variety of majors including environmental science, public policy, business, and engineering. Detroit provided an accessible, tangible, and local setting in which to explore the interrelated issues of social justice and sustainability. In this short essay, we describe what this experience taught us about service-learning courses and community engagement.

\section{Course Goals and Logistics}

The course first met on campus at the University of Michigan in Ann Arbor for eight weeks, with field trips to Detroit interspersed, and then reconvened for a twoweek immersion period in Detroit. The goals of the course were 1) to allow students to apply classroom-based sustainability learning to practical experiences that would either challenge or reinforce ideas presented in the classroom, and 2) to create an engaging interdisciplinary learning environment that would provide academically diverse students with opportunities not available in most sustainability classes. The instructors and students worked with an environmental justice community group, Southwest Detroit Environmental Vision (SDEV), to engage with residents living in Delray, a polluted and impoverished neighborhood in southwest Detroit (Figures 1 and 2).

The Delray neighborhood is the proposed landing site for the New International Trade Crossing (NITC). This controversial bridge project would likely bring elevated levels of air pollution and disruption to the neighborhood due to increased truck traffic, but also has the potential to improve local and state economies through bolstered trade. The community has been involved in discussions with local, state, and federal officials for several years in an attempt to ensure that the potential negative impacts of this project are minimized through a community benefits agreement. However, to successfully develop a contractual and legally binding community benefits agreement, the community wanted to create a cohesive plan detailing their future neighborhood vision and proposed improvements to protect the health and well-being of residents. In collaboration with SDEV, we decided that the students in this course would construct such a neighborhood plan based on input from community members. This collaborative effort allowed students to apply the urban planning and sustainability principles that they had learned in the classroom to residents' needs, which include housing relocation, air pollution reduction, brownfield remediation, pedestrian walkways, and connections to surrounding neighborhoods. 


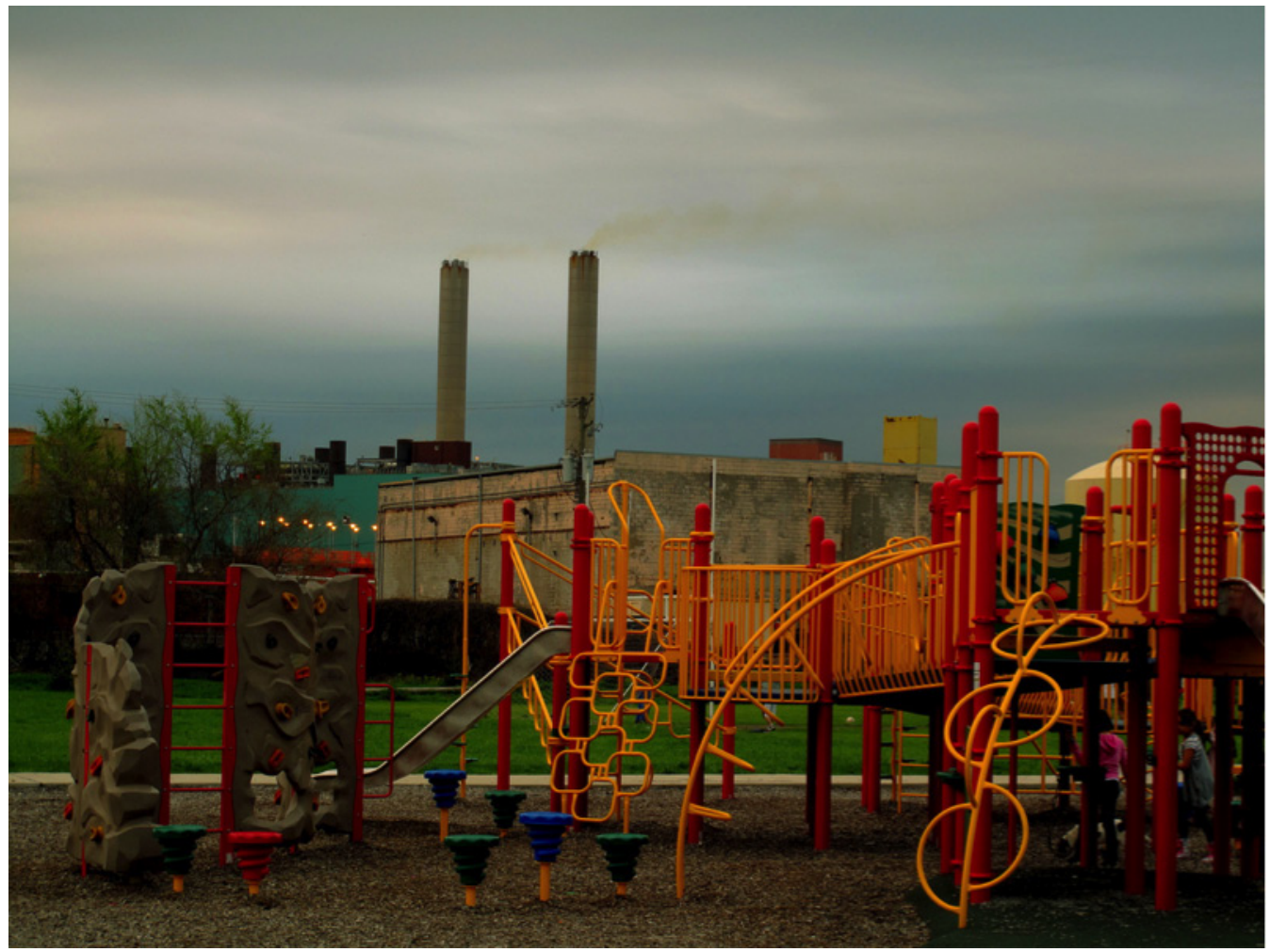

Figure 1: The Detroit Wastewater Treatment Plant forms the backdrop to the Delray Neighborhood House playground.

Throughout this course the students and instructors learned from each other, as well as from practitioners and community members, in our efforts to support onthe-ground policy and neighborhood change. More broadly, the course presented a unique opportunity to study how community-based experiences changed students' conceptions regarding sustainability and influenced student learning outcomes (Larsen et al., in review). Student learning and experiences were documented and measured using surveys and journal reflections.

\section{Community Engagement: Focus on the Action, Not the Philosophy}

The community-based nature of the course raised important questions about how educators and university students can best interact with less privileged residents. To facilitate these interactions, we organized three evening meetings at a neighborhood community center in collaboration with SDEV. To encourage residents to attend, 


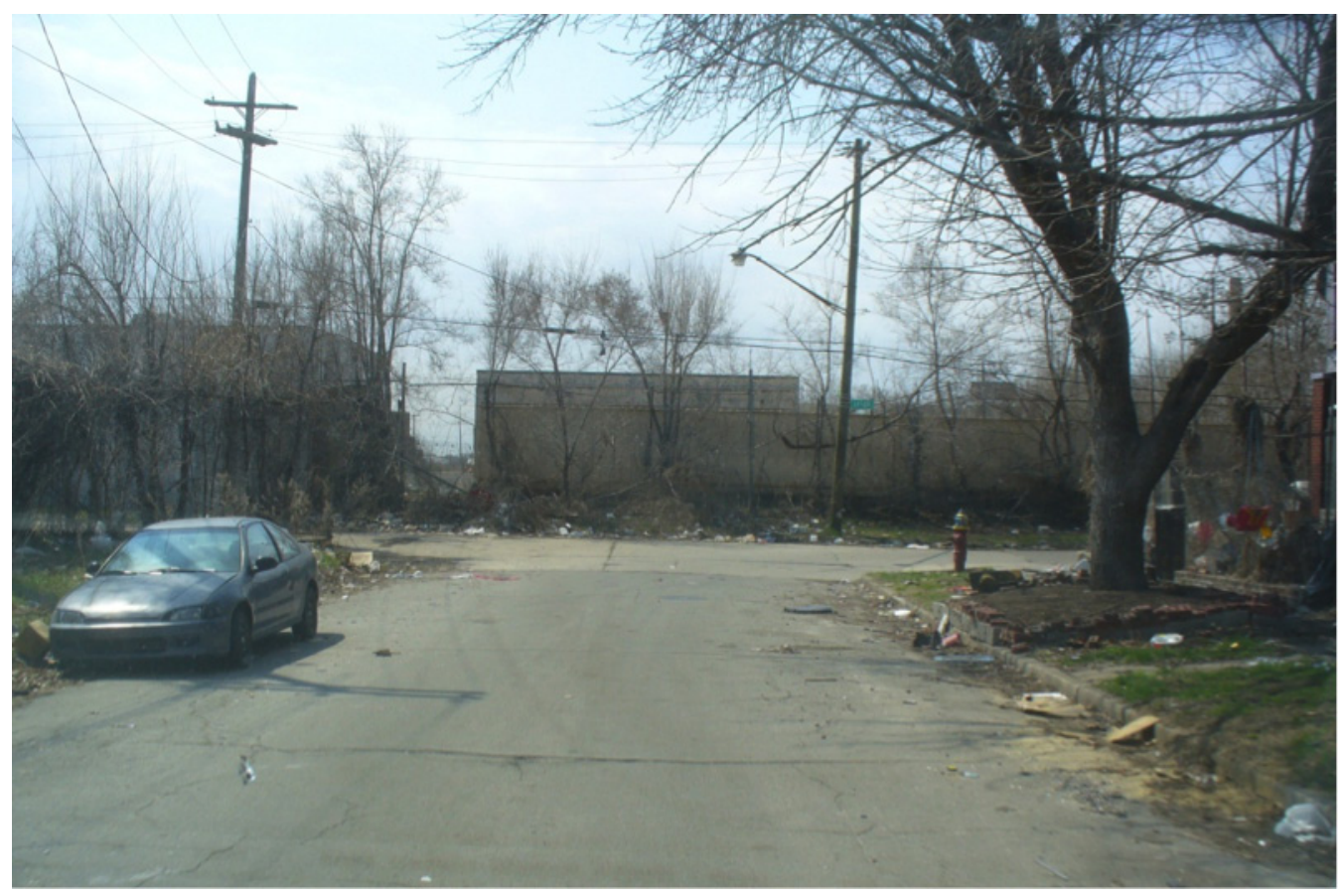

Figure 2: A street in Delray.

we made phone calls and provided dinner and childcare. Our collaboration with SDEV helped us build trust among the residents. This was particularly important given the socioeconomic and racial differences between the predominantly middleto upper-class white students and the predominantly impoverished African American and Hispanic residents. During the first two community meetings (Figure 3), students broke into small groups to learn about the neighborhood from residents and to collect information about the political, socioeconomic, and environmental challenges that the residents face. Students also asked residents about community assets and institutions they would like to see preserved. It was imperative that students set aside their preconceived notions of the residents' living circumstances and actually listen to what the residents had to say. For example, we encouraged students not to quickly say, "I understand ..." in response to residents' complaints about their living situations. Rather, students were instructed to ask relevant follow-up questions that would make residents feel comfortable sharing their stories and enable residents to consider potential solutions. In addition, students carefully documented residents' responses to questions about their concerns and vision for the neighborhood. This information was collected and used by the students to develop a final, cohesive neighborhood plan. The final neighborhood plan, which required detailed mapping 


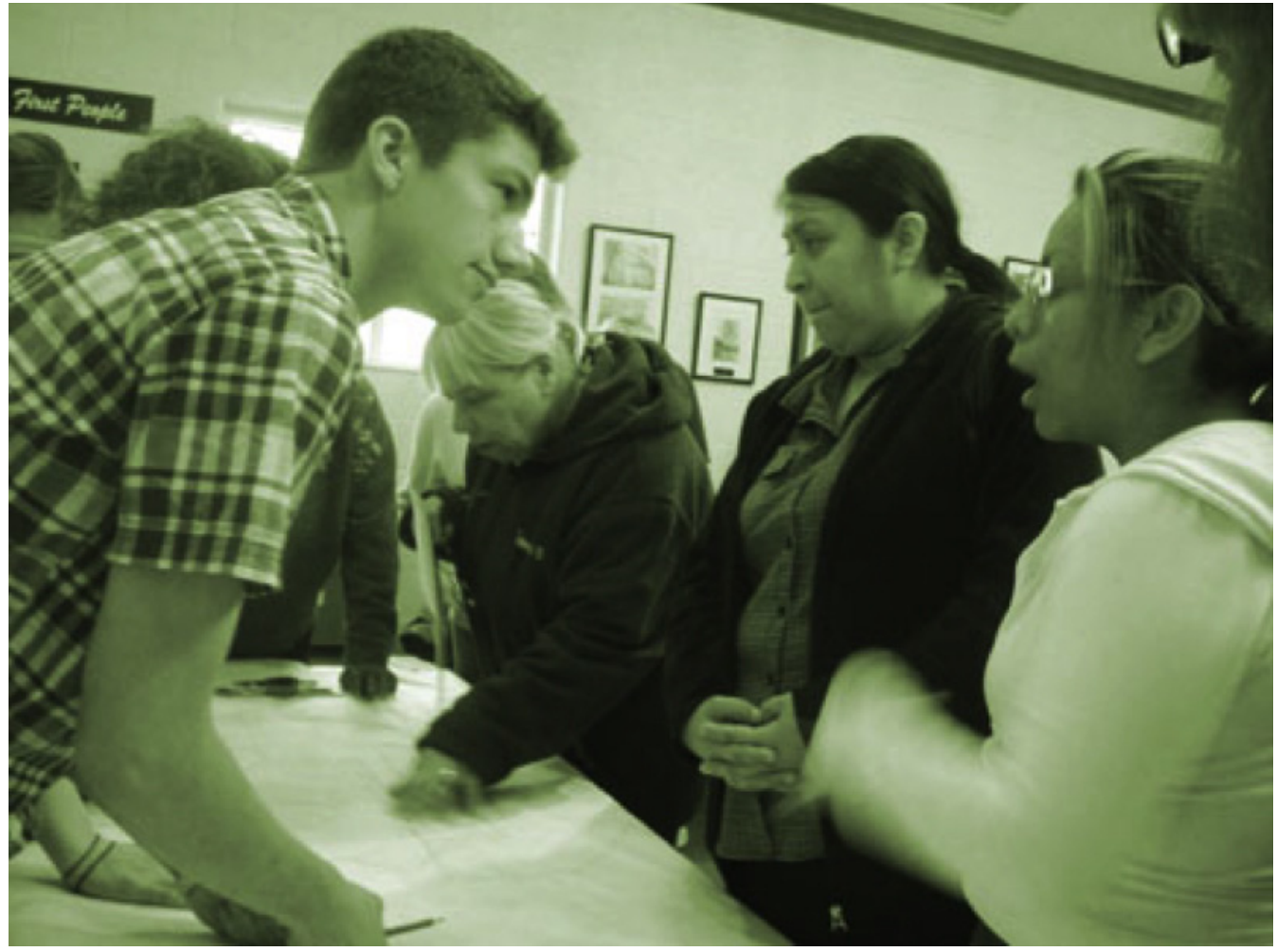

Figure 3: Students engaging with neighborhood residents at a community meeting.

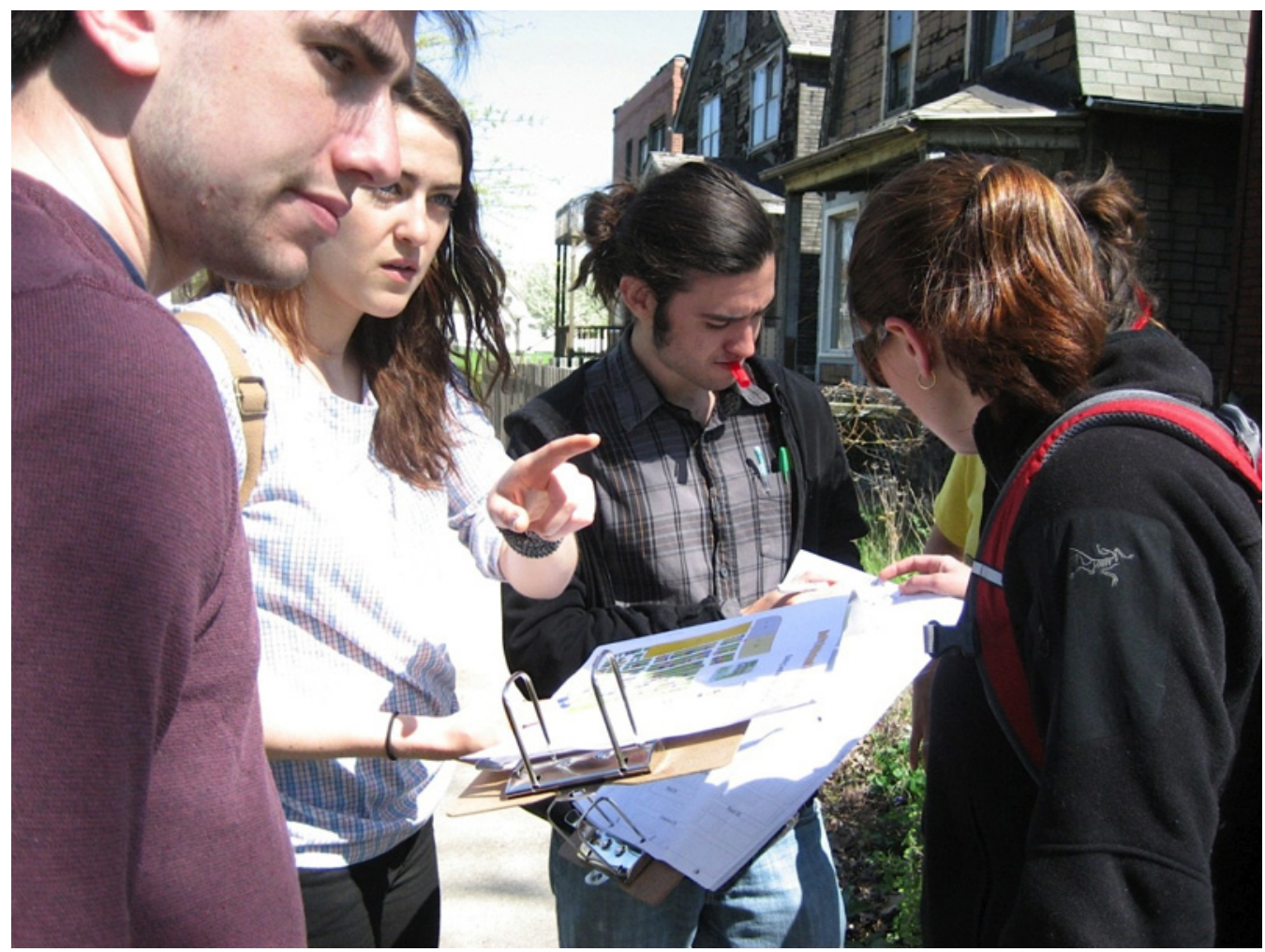

Figure 4: Students surveying inhabited, vacant, and abandoned lots in Delray. 


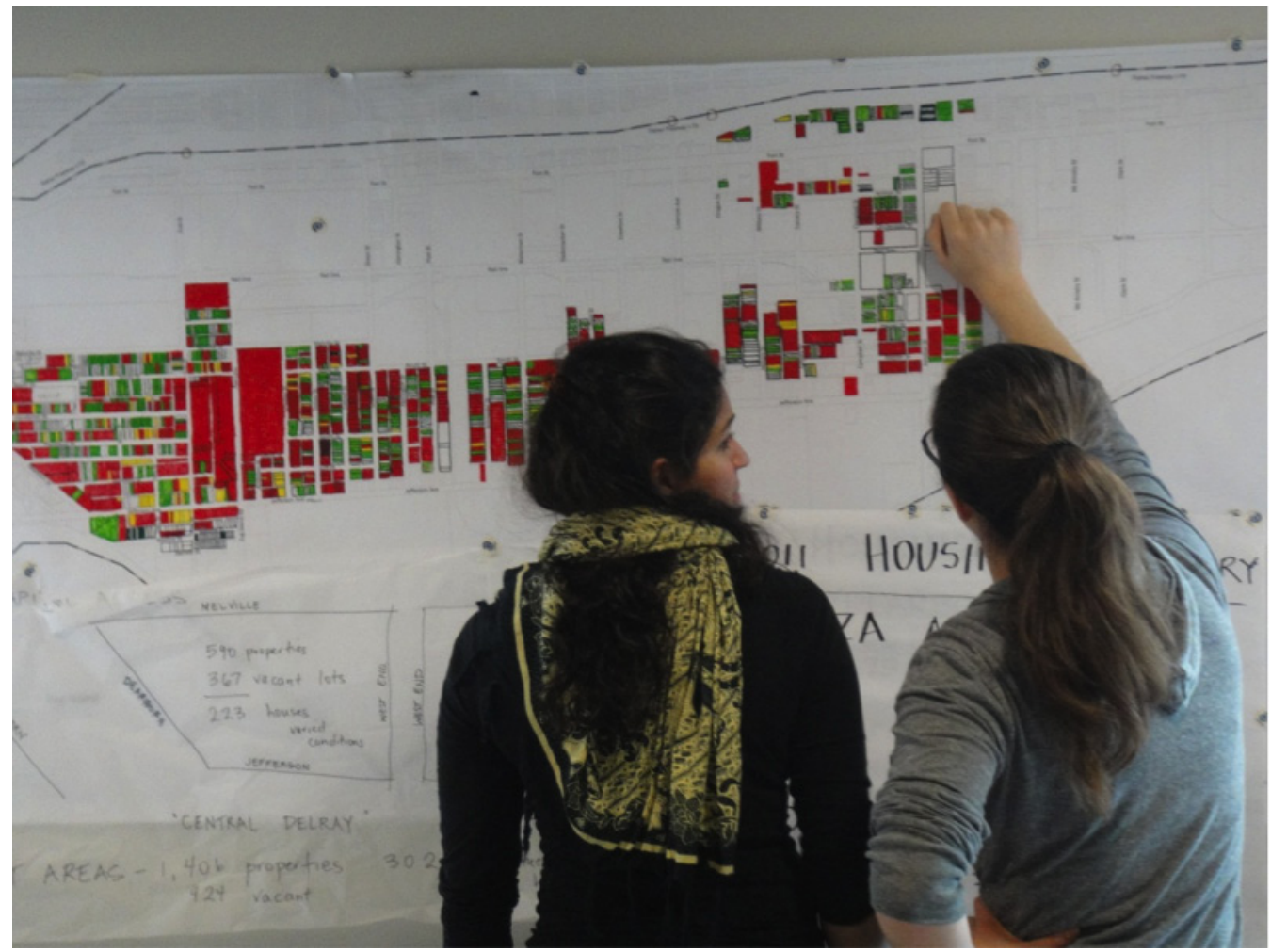

Figure 5: Students discussing a survey of land parcels in Delray.

of current neighborhood land parcels (Figures 4 and 5), included the proposed landing of the new bridge along with green spaces and greenways, connections to surrounding neighborhoods, and air and sound pollution buffers. In a final community meeting, two students presented this neighborhood plan to the residents.

To effectively communicate with the residents about social justice and sustainability, in addition to collaborating with SDEV, we found that it was necessary for students to modify their language. Maclaren (1996) describes six frameworks that communities can use to organize their urban sustainability indicators and actions towards achieving sustainability goals. When we entered the community, students wanted to organize residents' concerns using the broad domain-based framework of environment, economics, and equity that is widely used for sustainability-related thinking (Maclaren 1996). However, during the community meetings it became clear that the residents were not framing issues in the same ways as the students. While the students described the potential sustainability goals to community members in broad conceptual terms such as "improving the local economy" or "pro- 
tecting the environment," the residents tended to focus on specific issues, such as elevated levels of airborne fine particulate matter that affected their daily lives. During group discussions after the first community meeting, it became clear that the students recognized these differences in framing. For example, the excerpt below taken from a student journal reflects this realization:

While important information was gleaned [from the community meetings], it was never quite what we were hoping for, but this is to be expected [because] residents do not often think about their community in [broad] terms... Thus [our] questions [for community members] must be broken down into simpler forms from which answers to larger questions can be derived.

Students found that it was difficult to translate the concepts of a broad domainbased framework into clear, attainable community goals. Residents, in contrast, were using an issue-based framework to identify the specific problems in the neighborhood. Although the issue-based framework can sometimes result in a piece meal approach (Maclaren 1996) to issue coverage, we found that it was necessary for students to communicate with residents using this lens and then attempt to incorporate broader sustainability concepts. During group discussions we helped students to modify their language and shift to an issue-based framework.

\section{Service Learning and Community Engagement: Challenges and Outcomes}

Providing an outlet for meaningful action was one of the central successes of our course. Throughout the course, in group discussions and in reflective writings, the students emphasized that the work they did in Detroit felt important and tangible to them, and many students also indicated that the residents echoed these sentiments. College students often spend years doing coursework purely for a grade without observing any tangible "real-world" (i.e., non-academic) impact. We found that our students cherished the opportunity to learn while simultaneously putting their skills to work, and we hope the experience inspired them to seek future work in areas such as social justice, environmental sustainability and urban planning.

However, there are many challenges in developing, organizing, and teaching service-learning courses. Even though community engagement is a continual learning process for everyone involved, we found that our students expected us, as in- 
structors, to be leaders with the authority to certify correct approaches. It was important for us to be clear that there are no "right" or "wrong" answers in social justice and sustainability work. Instead, there may be several favorable outcomes to a problem, each with its own pros and cons. Furthermore, partnering with an established community group and developing trust between the community and academia is essential to the success of these courses and projects. In our case, trust was established over many years as the result of a long-term relationship between the faculty member, SDEV, and the Delray community.

Despite these challenges, service-learning courses fill an important gap in student learning. Indeed, deep involvement in a complicated case offers an unparalleled and concrete entry point for discussing broader ideas and for teaching the complexities of sustainability work. The detailed conversations that students had with residents added narrative to the students' previously abstract understanding of the social injustices and poor environmental conditions of the Delray neighborhood. By working in a neighborhood context, students were confronted with the structural limits to solving problems of social and environment justice, and some students left the course distressed about the unsustainability of our world. However, we believe that learning about these structural limitations forms an essential kind of knowledge for students who have engaged only abstractly with sustainability. Importantly, an analysis of student surveys taken before, during, and after the course showed that the Detroit immersion expanded students' definitions of sustainability to include factors that they did not originally consider, such as social justice and quality-of-life issues (Larsen et al., in review). These shifting definitions also suggested that students were moving from the theoretical notions of domain-based sustainability to more easily relatable issue-based thinking. Equipping students with the flexibility to think in both broad and specific sustainability terms is important to the development of students who can become effective practitioners and advocates for social change. In other words, broad, philosophical conceptions of sustainability must be constantly distilled, reworded, and conveyed in very concrete terms depending on the community, the audience, and the political and socio-ecological setting.

In summary, service-learning courses have the potential to connect academics, practitioners, and the broader public to create an environment in which each group meaningfully learns from the others. Service learning can ground what is taught in classrooms within a real-world context and emphasizes the knowledge and skills that will likely become relevant to students once they graduate and assume roles in public life and citizenry. 


\section{References}

Dewar, M. E., and C. B. Isaac. 1998. "Learning from Difference: The Potentially Transforming Experience of Community-University Collaboration." Journal of Planning Education and Research 17 (4): 334-347. http://dx.doi.org/10.1177/0739456X9801700408

Larsen, L., L. S. Sherman, L. B. Smith, D. M. A. Karwat, K. C. Badiane, and P. J. Coseo. Forthcoming. "Social Justice and Sustainability in Poor Neighborhoods: Learning and Living in Southwest Detroit." Journal of Planning Education and Research.

Maclaren, V. W. 1996. "Urban Sustainability Reporting." Journal of the American Planning Association 62 (2): 184-202. http://dx.doi.org/10.1080/01944369608975684

Roakes, S. L., and D. Norris-Tirrell. 2000. "Community Service Learning in Planning Education: A Framework for Course Development." Journal of Planning Education and Research 20 (1): 100-110. http://dx.doi.org/10.1177/073945600128992636

Umemoto, K. 2001. "Walking in Another's Shoes: Epistemological Challenges in Participatory Planning." Journal of Planning Education and Research 21: 17-31. http://dx.doi. org/10.1177/0739456X0102100102 